\title{
La fiscalidad de los bienes de interés cultural
}

\author{
Vicente Fernández Guerrero, letrado de la Junta de Andalucia, jefe de la Asesoría Jurídica de la Agencia Tributaria de Andalucía
}

\section{INTRODUCCIÓN}

Es el propósito de quien suscribe ofrecer a los destinatarios de esta publicación una panorámica de la fiscalidad que afecta a los bienes de interés cultural, resaltando las singularidades tributarias que los gestores del patrimonio cultural necesitan conocer en su gestión ordinaria. No alcanza por tanto el carácter de una obra científica o investigadora, sino más bien un artículo de carácter divulgativo, producto más de la recensión, resumen, actualización y simplificación de obras que si tienen aquel carácter, no constituyendo el producto de una esmerada elaboración propia. Vaya por delante esa advertencia.

La finalidad y destinatarios de esta revista han llevado al autor a seguir la forma de redacción que se ha descrito, en el entendimiento de que la bibliografia que se cita al final de este artículo permitirá a aquéllos que lo deseen o necesiten profundizar en el análisis de la fiscalidad de los bienes de interés cultural. Dicho lo anterior, trataremos de seguir en este artículo el orden y contenido expositivo de la obra más sistemática y completa a que se ha tenido acceso. El artículo publicado por la profesora titular de Derecho Financiero y Tributario de la Universidad de Granada Rancaño Martín en el número anual correspondiente a 2007 de la revista de la Facultad de Derecho de dicha Universidad que lleva por título La tributación del patrimonio histórico español.

Al margen de este análisis queda la cuestión de los beneficios fiscales de quienes apoyan actividades de interés cultural general. A esta cuestión se dedica particularmente la Ley 49/2002, de régimen fiscal de las entidades sin fines lucrativos y de los incentivos fiscales al mecenazgo, cuyo artículo 25 establece un régimen fiscal privilegiado para los convenios de colaboración empresarial en actividades de interés general, por supuesto el interés cultural general incluido. Nos remitimos a quien quiera profundizar en este punto al estudio publicado en el Anuario de la Facultad de Derecho de la Universidad de Extremadura (HERNÁNDEZ LAVAD0: 2009, pp. 37-54).

Vaya también por delante la utilización a los fines de este artículo de la definición de bienes de interés cultural o patrimonio cultural más comúnmente empleada por la doctrina internacional: el conjunto de bienes, materiales e inmateriales, que son identificados por una sociedad concreta como portadores culturales propios de la comunidad; son bienes tangibles e in- tangibles que tienen un alto contenido simbólico, lo que les hace merecedores de una especial protección no sólo relacionada con su conservación, sino también con el uso que se pueda hacer de ellos. Con todo, esa definición, a los efectos fiscales, no trasciende, habida cuenta de la tradicional asunción en el ordenamiento tributario de la preferencia a tales fines de las definiciones de los conceptos que se recogen en esa parte del ordenamiento jurídico.

Ha de finalizarse esta introducción destacando cómo las medidas fiscales atinentes a los bienes de interés cultural han provocado efectos inimaginables al tiempo de plantearse por parte del legislador estatal. Uno de los más famosos ha sido la titularidad que durante más de una década mantuvo la Junta de Andalucia respecto del inmueble conocido como la casa de las Conchas en Salamanca. Dicha titularidad derivó del pago por un sujeto pasivo de la cuota del impuesto sobre sucesiones y donaciones mediante la entrega a la Hacienda autonómica de Andalucia de la titularidad de dicho bien. Curioso caso de titularidad "extraterritorial" por parte de las administraciones autonómicas de bienes de interés cultural.

\section{EL FOMENTO DEL PATRIMONIO CULTURAL: ACCESO PREFERENTE AL CRÉDITO OFICIAL Y "UNO POR CIEN CULTURAL"}

La Ley de patrimonio histórico español de 1985 vino a establecer determinadas medidas de fomento del patrimonio cultural. Entre ellas no sólo se encuentran una serie de beneficios fiscales, sino también una preferencia en cuanto al acceso al crédito oficial de la financiación de obras de conservación, mantenimiento y rehabilitación de ese patrimonio (art. 67).

Junto a la adopción de dichas medidas también se prevé la necesaria consignación de un porcentaje del presupuesto de cada obra pública que irá destinado a financiar trabajos de conservación o enriquecimiento del patrimonio cultural (art. 68). Esto es lo que comúnmente se conoce como el "uno por cien cultural".

\section{LOS BENEFICIOS FISCALES DEL PATRIMONIO CULTURAL}

La Ley de patrimonio histórico español recoge una serie de normas generales para el disfrute de beneficios fiscales en relación 
con el patrimonio cultural. Asi, para disfrutar de estos beneficios, los bienes deberán ser inscritos previamente en el Registro General, en el caso de bienes de interés cultural, o en el Inventario General, en el supuesto de bienes muebles del patrimonio histórico no declarados de interés cultural que tengan singular relevancia (art. 69). Esta circunstancia ha sido criticada por la Doctrina por cuanto se excluye de la aplicación de los beneficios fiscales a los bienes de interés cultural que no estén inscritos, aún cuando a sus titulares se les imponen las cargas y obligaciones derivadas de su calificación como bienes del patrimonio histórico. Con todo, los beneficios fiscales recogidos en la Ley del patrimonio histórico español en muchos casos han sido derogados por leyes tributarias posteriores, por lo que en algunos casos los beneficios fiscales se aplican a bienes no inscritos en el Registro General de Bienes de Interés Cultural o en el Inventario General.

a) El impuesto sobre la renta de las personas físicas

La Ley 35/2006, del IRPF, recoge (art. 14.2.j) una regla especial de imputación temporal de las ayudas públicas otorgadas por las administraciones competentes a los titulares de bienes de interés cultural inscritos en el Registro General, cuando dichas ayudas están destinadas a su conservación y rehabilitación: dichas ayu-

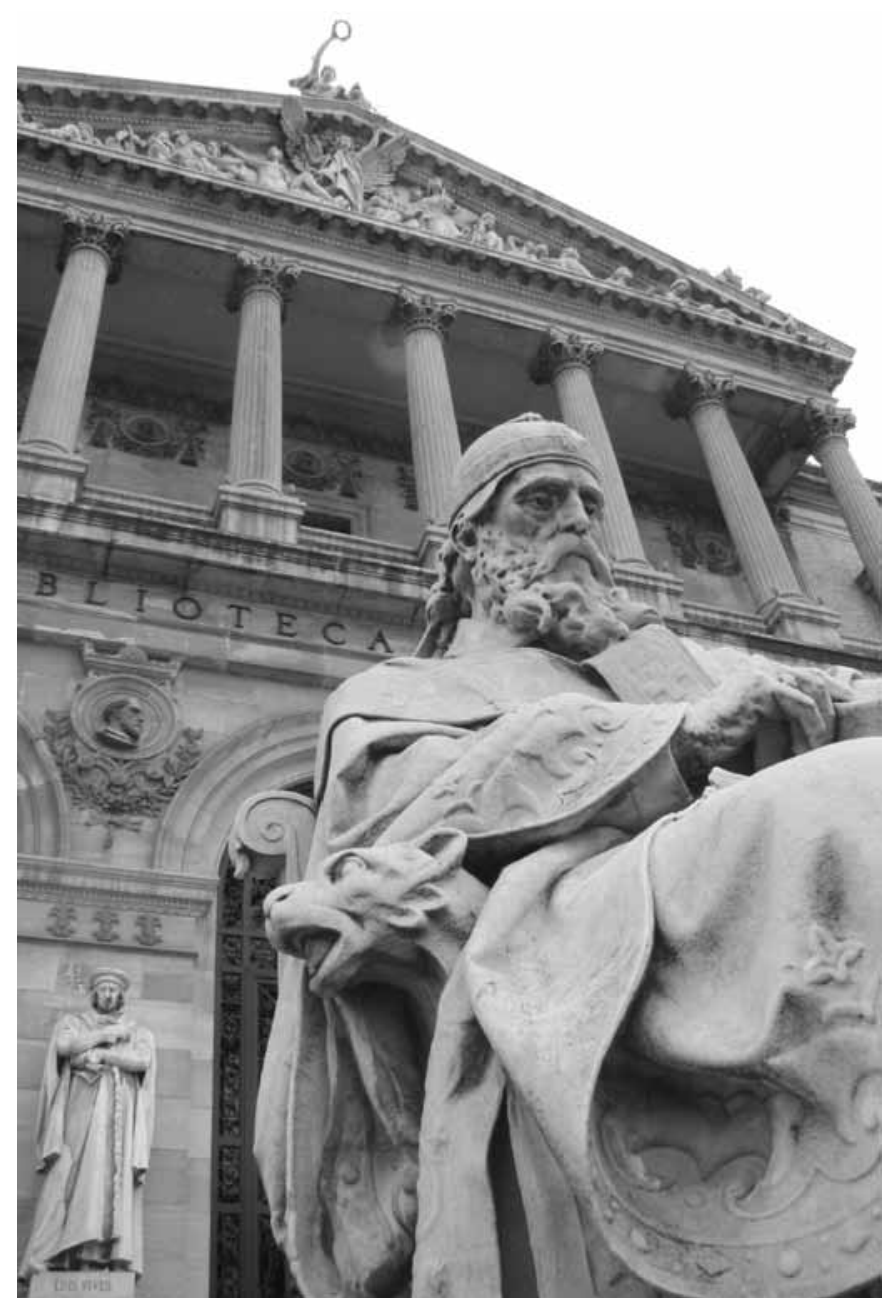

Biblioteca Nacional (Madrid). Foto: Carmen García Bueno das podrán imputarse por cuartas partes en el periodo impositivo en que se obtengan y en los tres siguientes, siempre y cuando se cumplan las exigencias establecidas en la norma, particularmente en lo referido al cumplimiento de los deberes de visita y exposición pública de dichos bienes.

También es destacable la previsión de una deducción en la cuota del 15\% del importe de las inversiones o gastos que se realicen por actuaciones para la protección y difusión del patrimonio histórico español y de las ciudades, conjuntos y bienes declarados patrimonio mundial (art. 68.5).

El art. 97.3 de la Ley del IRPF también ha extendido la posibilidad de pagar la deuda tributaria correspondiente a este impuesto mediante la entrega de bienes integrantes del patrimonio cultural inscritos en el Registro General o en el Inventario General de Bienes Muebles.

\section{b) El impuesto sobre sociedades}

El art. 9 del texto refundido de la Ley de este impuesto (RDLeg 4/2004) prevé la exención en el impuesto sobre sociedades de las rentas obtenidas por entidades sin fines lucrativos que procedan de las explotaciones económicas recogidas en dicho precepto. Y se pueden acoger a esta exención las explotaciones económicas de los bienes declarados de interés cultural, así como de museos, bibliotecas, archivos y centros de documentación, siempre y cuando se cumplan las tradicionales exigencias respecto de los deberes de visita y exposición pública de dichos bienes.

Del mismo modo debe reseñarse la previsión de una deducción en la cuota del 15\% del importe de las inversiones o gastos que se realicen por actuaciones para la adquisición, conservación y rehabilitación de los bienes de interés cultural (art. 38).

En correspondencia también con la normativa del IRPF, se contempla en el art. 137.2 del texto refundido la posibilidad de pagar la cuota correspondiente a este impuesto mediante la entrega de bienes integrantes del patrimonio cultural inscritos en el Registro General o en el Inventario General de Bienes Muebles.

c) El impuesto sobre el patrimonio

El art. 4 de la Ley 19/1991, del impuesto sobre el patrimonio, declara exentos de este impuesto la titularidad de bienes del patrimonio histórico español inscritos en el Registro General o en el Inventario General de Bienes Muebles, así como también a los bienes integrantes del patrimonio histórico de las CC. AA. que hayan sido calificados e inscritos de acuerdo con sus normas reguladoras. Téngase en cuenta que no están incluidos en la exención los inmuebles situados en conjuntos o sitios históricos que no estén incluidos en el Catálogo previsto en el art. 86 del Reglamento de Planeamiento Urbanístico como objeto de protección integral. 


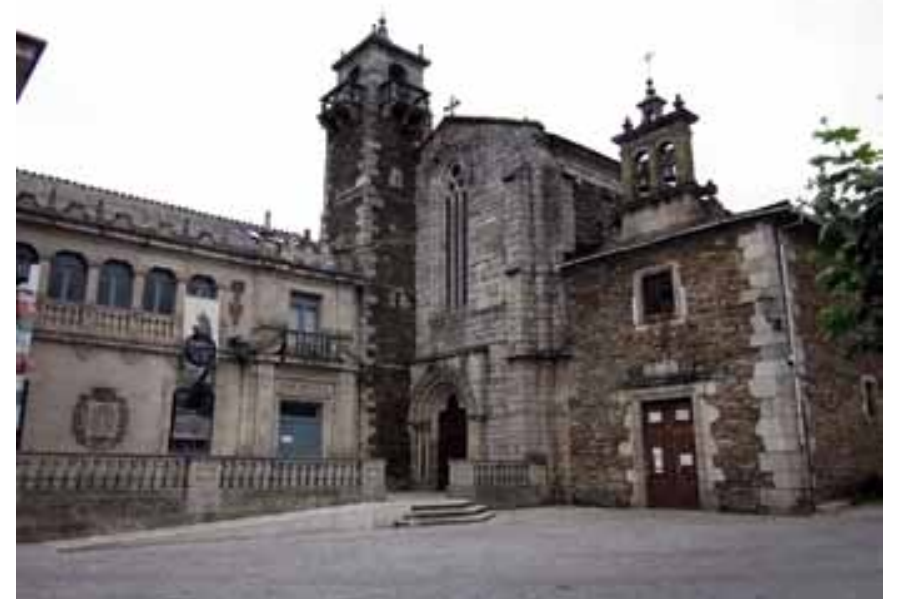

Museo provincial de Lugo. Foto: Agus Muñoz

\section{La ley del impuesto de sociedades prevé la exención del mismo para museos, bibliotecas, archivos y centros de documentación, siempre y cuando se cumplan las tradicionales exigencias respecto de los deberes de visita y exposición pública de dichos bienes}

También se puede pagar la cuota de este impuesto mediante la entrega de bienes de interés cultural inscritos en el Registro General o en el Inventario General de Bienes Muebles (art. 36).

\section{d) El impuesto sobre sucesiones y donaciones}

Lo más reseñable de la regulación de este impuesto (Ley 29/1987, de 18 de diciembre) es que, cuando en la base imponible del impuesto figuren bienes del patrimonio histórico español o del patrimonio histórico o cultural de las CC. AA., se aplicará una reducción en la base imponible del 95\% de su valor.

Igual que sucede con los tributos que ya se han expuesto, también se puede pagar la cuota de este impuesto mediante la entrega de bienes de interés cultural inscritos en el Registro General o en el Inventario General de Bienes Muebles (art. 36).

e) El impuesto sobre transmisiones patrimoniales y actos juridicos documentados

Al margen de un tratamiento fiscal favorable por razón del sujeto que participa en los negocios jurídicos gravados por este impuesto, la ley sólo bonifica la transmisión onerosa de bienes integrantes del patrimonio cultural cuando su destino sea el desarrollo de acontecimientos de excepcional interés público. Las restantes transmisiones de estos bienes no quedan exentas de este impuesto salvo que el sujeto pasivo sea una entidad sin fin lucrativo.

\section{f) El impuesto sobre el valor añadido}

Gozan de exención las siguientes operaciones de prestaciones de servicios efectuadas por entidades de derecho público o por entidades o establecimientos culturales privados de carácter social (art. 20 Ley IVA):

- Las propias de bibliotecas, archivos y centros de documentación; - las visitas a museos, galerías de arte, pinacotecas, monumentos, lugares históricos, jardines botánicos, parques zoológicos y parques naturales y otros espacios naturales protegidos de caracteristicas similares;

- las representaciones teatrales, musicales, coreográficas, audiovisuales y cinematográficas;

- la organización de exposiciones y manifestaciones similares.

g) El impuesto sobre bienes inmuebles

El art. 62.2.b) del RDLeg 2/2004, por el que se aprueba el texto refundido de la Ley de haciendas locales, establece que estarán exentos, siempre previa solicitud, los inmuebles declarados expresa e individualizadamente monumento o jardín histórico de interés cultural, mediante real decreto en la forma establecida por el art. 9 de la Ley del patrimonio histórico español e inscritos en el Registro General como integrantes del patrimonio histórico español.

También estarán exentos, previa solicitud, los comprendidos en las disposiciones adicionales primera, segunda y quinta de la Ley del patrimonio histórico español, que son:

- Los inmuebles que con anterioridad a dicha ley hubieran sido declarados histórico-artísticos o incluidos en el Inventario del patrimonio artístico y arqueológico de España;

- los inmuebles a que se contraen los decretos de 22 de abril de 1949, 571/1963 y 499/1973;

- Ios inmuebles que formen parte del Patrimonio Nacional.

Esta exención no alcanzará a cualesquiera clases de bienes urbanos ubicados dentro del perimetro delimitativo de las zonas arqueológicas y sitios y conjuntos históricos, globalmente integrados en ellos, sino, exclusivamente, a los que reúnan las siguientes condiciones:

- En zonas arqueológicas, los incluidos como objeto de especial protección en el instrumento de planeamiento urbanistico a que se refiere el art. 20 de la Ley del patrimonio histórico español.

- En sitios o conjuntos históricos, los que cuenten con una antigüedad igual o superior a cincuenta años y estén incluidos en el catálogo previsto en el Reglamento de Planeamiento, como objeto de protección integral en los términos previstos en el art. 21 de la Ley del patrimonio histórico español.

Esta regulación es bastante más restrictiva para la concesión de exenciones que la que existía en el texto refundido de 12 de 
mayo de 1966, sobre la Contribución Territorial Urbana, el cual, a diferencia de la regulación vigente, extendia la exención, genéricamente, a todos los inmuebles integrados en el patrimonio histórico artístico.

Con mucho, el impuesto sobre bienes inmuebles ha sido la figura tributaria que mayor conflictividad ha ocasionado respecto del patrimonio cultural. Izard Anaya ha recopilado una serie de pronunciamientos jurisdiccionales, la mayoría de ellos de carácter restrictivo, por incumplimiento de los requisitos exigidos para el disfrute del beneficio fiscal considerado, y denegadores, por tanto, de la exención en el IBI solicitada por los titulares de los mismos (IZARD ANAYA, 2006).

Así pueden citarse, entre otras, la sentencia del Tribunal Superior de Justicia de Murcia de 18 de febrero de 1997 -en la que se denegó la exención para un bien inmueble, que tenía el carácter de finca de interés cultural, porque el mismo no podia ser incardinado en ninguno de los supuestos anteriormente expuestos-; la sentencia del Tribunal Superior de Justicia de Galicia de 20 de marzo de 1997, cuya doctrina se reitera en la sentencia de este mismo órgano de 30 de mayo de 1997 -en la que se declaró que no procedía la exención en favor de tres inmuebles integrados en el casco histórico de Santiago de Compostela, al no haber sido declarado los edificios, de forma expresa e individualizada, monumentos históricos, sin que pudiese entenderse que la inclusión de los mismos en el Catálogo de edificios a proteger regulado en el art. 25 de la Ley del suelo (TR de 1976) fuese equivalente a la declaración como monumentos históricos, añadiéndose en esta sentencia: "En todo caso, conviene recordar lo que se dijo en la precitada Sentencia del Tribunal Supremo de 24 de febrero de 1995, en el sentido de que la inclusión de un inmueble en el catálogo de edificios a proteger que se regula en el art. 25 TR de la Ley del suelo, no supone por sí misma una limitación de las facultades dominicales de idéntica naturaleza y amplitud que las establecidas para los edificios declarados monumentos, sino que dentro de los catálogos urbanísticos se establecen distintas medidas de protección en función de las caracteristicas del inmueble a proteger. $Y$ así, en el caso de autos, tales limitaciones consistieron en suspensión del otorgamiento de licencias de reparcelación, construcción y derribo por término de un año, sin perjuicio de conceder licencias que respetasen las determinaciones del nuevo planeamiento, limitaciones que no alcanzan la importancia de las previstas en la Ley del patrimonio histórico, y que, en todo caso, como bien se expresa en la resolución recurri$\mathrm{da}$, fueron tenidas en cuenta por la Ponencia de Valores mediante la aplicación de indices correctores"-, y la sentencia del Tribunal Superior de Justicia de Extremadura de 14 de abril de 1997, en la que se denegó la exención porque si bien estaba acreditado que una finca urbana, construida en el año 1870, aparecía incluida en el catálogo de edificaciones protegidas, también lo estaba que dicho inmueble no había sido declarado monumento de interés cultural, no habiéndose iniciado siquiera la incoación del correspondiente expediente para tal declaración.
Frente a tales pronunciamientos de diversos tribunales de justicia, constituye una excepción lo acordado por el Tribunal Superior de Justicia de Cataluña en su sentencia de 11 de abril de 1997, en donde sí se otorga la exención pedida en el IBI en favor del castillo de Cerdanyola, ya que en este caso el referido inmueble si era merecedor de dicho beneficio fiscal, al haberse dispuesto que el mismo fuese inscrito en el Registro General de Bienes de Interés Cultural del Patrimonio Histórico Español, con la categoria de monumento, en virtud de una previa resolución de la Dirección General de Bellas Artes y Archivos del Ministerio de Cultura de 11 mayo 1987.

h) El impuesto sobre incremento del valor de los terrenos de naturaleza urbana

Dispone la Ley de haciendas locales (art. 105) que estarán exentos de este impuesto los incrementos de valor que se manifiesten como consecuencia de las transmisiones de bienes que se encuentren dentro del perímetro delimitado como conjunto histórico-artístico, o hayan sido declarados individualmente de interés cultural, según lo establecido en la Ley del patrimonio histórico español, cuando sus propietarios o titulares de derechos reales acrediten que han realizado a su cargo obras de conservación, mejora o rehabilitación en dichos inmuebles. A estos efectos, la ordenanza fiscal establecerá los aspectos sustantivos y formales de la exención, condicionamiento que implica que la aplicación de la exención depende del desarrollo reglamentario por medio de la correspondiente ordenanza fiscal.

\section{i) El impuesto sobre construcciones, instalaciones y obras}

La Ley de haciendas locales permite que las ordenanzas fiscales establezcan una bonificación del 95\% de la cuota a favor de las construcciones, instalaciones u obras que sean declaradas de especial interés o utilidad municipal por concurrir circunstancias sociales, culturales, histórico artísticas o de fomento del empleo que justifiquen tal declaración. Corresponderá dicha declaración al Pleno de la Corporación y se acordará, previa solicitud del sujeto pasivo, por voto favorable de la mayoría simple de sus miembros.

\section{Bibliografía}

FERNÁNDEZ DE SOTO BLASS, M. L. (2006) La tributación del patrimonio histórico español. Impuestos, n. ${ }^{\circ}$ 4, 2006, pp. 9 y ss.

HERNÁNDEZ LAVADO, A. (2009) La fiscalidad del convenio empresarial en actividades de patrocinio a patrimonio cultural. Anuario de la Facultad de Derecho de la Universidad de Extremadura, n. ${ }^{\circ} 27,2009$, pp. 37 y ss.

IZARD ANAYA, B. (2006) Las exenciones en el impuesto sobre bienes inmuebles: el RDLeg 2/2004 y demás normas de aplicación. Cizur Menor (Navarra): Aranzadi, 2006, pp. 168 y ss.

MARTÍN FERNÁNDEZ, F. J. (1992) El patrimonio histórico español y los nuevos impuestos sobre la renta y el patrimonio de las personas físicas. Revista española de derecho financiero y hacienda pública, n. ${ }^{\circ} 220,1992$, pp. 823 y ss.

MUÑOZ DEL CASTILLO, J. L.; VEGA HERRERO, M.; VAOUERA GARCÍA, A. (2004) Beneficios fiscales al patrimonio histórico español. León: Universidad de León, Secretariado de Publicaciones y Medios Audiovisuales, 2004, p. 12

RANCAÑO MARTíN, M. A. (2007) La tributación del patrimonio histórico español. Revista de la Facultad de Derecho de la Universidad de Granada, n. ${ }^{\circ}$ 10, 2007, pp. 133 y ss. 